\title{
Spatial Assessment of the Association between Long-Term Exposure to Environmental Factors and the Occurrence of Amyotrophic Lateral Sclerosis in Catalonia, Spain: A Population-Based Nested Case-Control Study
}

\author{
Mònica Povedano ${ }^{\mathrm{a}}$ Marc Saez ${ }^{\mathrm{b}, \mathrm{c}}$ Juan-Antonio Martínez-Matos ${ }^{\mathrm{a}}$ \\ Maria Antònia Barceló ${ }^{\mathrm{a}-\mathrm{c}}$ \\ ${ }^{a}$ Functional Motoneurona Unit (UFMNA), Bellvitge Biomedical Research Institute (IDIBELL), L'Hospitalet de \\ Llobregat, Barcelona, Spain; ${ }^{\mathrm{b}}$ Research Group on Statistics, Econometrics and Health (GRECS), University of Girona, \\ Girona, Spain; ${ }^{C}$ CIBER of Epidemiology and Public Health (CIBERESP), Madrid, Spain
}

\section{Keywords}

Amyotrophic lateral sclerosis · Environmental variables · Pesticides · Air pollutants · Unobserved confounding $\cdot$ Spatial dependence

\begin{abstract}
Background: It is believed that an interaction between genetic and non-genetic factors may be involved in the development of amyotrophic lateral sclerosis (ALS). With the exception of exposure to agricultural chemicals like pesticides, evidence of an association between environmental risk factors and ALS is inconsistent. Our objective here was to investigate the association between long-term exposure to environmental factors and the occurrence of ALS in Catalonia, Spain, and to provide evidence that spatial clusters of ALS related to these environmental factors exist. Methods: We carried out a nested case-control study constructed from a retrospective population-based cohort, covering the entire region. Environmental variables were the explanatory variables of interest. We controlled for both observed and unob-
\end{abstract}

(c) 2018 S. Karger AG, Basel

E-Mail karger@karger.com www.karger.com/ned served confounders. Results: We have found some spatial clusters of ALS. The results from the multivariate model suggest that these clusters could be related to some of the environmental variables, in particular agricultural chemicals. In addition, in high-risk clusters, besides corresponding to agricultural areas, key road infrastructures with a high density of traffic are also located. Conclusion: Our results indicate that some environmental factors, in particular those associated with exposure to pesticides and air pollutants as a result of urban traffic, could be associated with the occurrence of ALS.

(c) 2018 S. Karger AG, Basel

\section{Introduction}

Amyotrophic lateral sclerosis (ALS) is a rapidly progressing, neurodegenerative disease characterized by a progressive loss of upper and lower motor neurons that leads to muscular atrophy, paralysis and patient death, usually due to respiratory failure [1-4]. Different pheno- 
types and presentations of ALS have been identified and are defined by where the symptoms of the disease first appear (spinal, bulbar, flail leg, flail arm, pyramidal or respiratory), by whether the upper or lower motor neuron is most affected (primary lateral sclerosis, progressive muscular atrophy and classic ALS) and by the rate the disease progresses (fast or slow). The overriding importance of these different phenotypes is in their prognosis because some are less incapacitating and spread more slowly than others and, unfortunately, for the others the prognosis is worse for the problems highlighted $[5,6]$. Spinal and bulbar phenotypes account for 42.0 and $33.5 \%$, respectively, of the total cases of ALS, while the flail leg phenotype accounts for $8.5 \%$ of all cases, the flail arm $6.5 \%$, pyramidal $5 \%$ and respiratory phenotype $4.5 \%$ [5, 6]. Genetic mutations do not entirely explain this heterogeneity because the same mutation can be associated with a large variability of ALS phenotypes. The dominantly inherited familial ALS, for which heredity is mainly autosomal dominant, only accounts for $10 \%$ of all ALS patients. Sporadic ALS has no apparent heritability and is the most common form of ALS. Although considerable progress has been made in understanding the genetics of familial ALS, the underlying causes of sporadic ALS remain unknown $[7,8]$. So far, the only recognized ALS risk factors are advanced age, being male and having a family history of ALS [9].

In a very recent meta-analysis, which included 825 million person-years of follow-up and covered 45 geographical areas in 11 sub-continents, Marin et al. [10], estimate the overall worldwide crude incidence of ALS equal to 1.75 per 100,000 persons/years of follow-up (95\% CI 1.55-1.96) with a standardized incidence of 1.68 (95\% CI 1.50-1.85). However, the geographical distribution of ALS incidence is very heterogeneous. The incidence of ALS in Europe has been estimated at around $2-4$ cases per 100,000 person/years [8]. This estimate is somewhat smaller in northern Europe where ALS standardized incidence is 1.89 per 100,000 persons/years (95\% CI 1.46-2.3) [10], although it is found to be higher in western Europe. In a systematic review of population-based observational studies, including 37 articles, Chiò et al. [5] estimated the incidence in western Europe for the period $1995-2011$ as 5.40 per 100,000 and 4.70 per 100,000 in 2012. In Spain, Santurtún et al. [11] found an annual incidence ranging from 1 to 3 cases per 100,000 inhabitants in 2013, while for the same year, Pradas et al. [12] estimated an annual incidence of 1.4 per 100,000 inhabitants in the Catalonia region (north-eastern Spain). In Asia, the incidence is much lower than in Europe. The ALS standardized incidence is 0.83 per 100,000 persons/years ( $95 \%$ CI $0.42-1.24$ ) for Eastern Asia and 0.73 per 100,000 persons/years (95\% CI 0.58-0.89) for Southern Asia [10]. However, for the same period in Japan, the ALS incidence was estimated equal to 2.2 per 100,000 persons/years [13]. The prevalence of ALS has been estimated to be between 5 [14] and 5.4 per 100,000 inhabitants [9]. Geographic variability also occurs. The highest figures are reported for Japan: 9.9 per 100,000 inhabitants in 2013 [13], practically twice as many as in the United States (3.9 per 100,000 inhabitants in 2010-2011 [13], 4.3 in 2013 [15]) and Europe (4.06 per 100,000 inhabitants in western Europe [5]), both with fairly similar prevalence. Pradas et al. [12] estimate a prevalence of 5.4 per 100,000 inhabitants for Catalonia, Spain.

Both in terms of the prevalence and incidence of ALS, heterogeneity also occurs with other variables such as sex and age. The incidence for men is between 1.3 and 1.5 higher than that of women $[15,10,12]$. ALS is rare before the age of 40 years, with the mean age at onset ranging from 58 to 63 years for the sporadic form and 40 to 60 years for the familial form [9]. There is very little variation between the phenotypes $[5,6]$. Subsequent to the age of onset, the incidence of ALS increases and peaks after 60 years of age. Chiò et al. [5] found that the incidence of ALS reaches its maximum from 60 to 75 years of age. However, in the Cima study, this maximum occurs from 65 to 74 years of age [16], while in several studies in Nova Scotia, Canada, from 70 to 79 years old [17].

The heterogeneity and prevalence in the incidence of ALS may be a consequence of different diagnostic criteria, clinical practices and ways of recording cases. However, an important part of the heterogeneity can be attributed to the interrelationship between genetic and non-genetic factors $[8,18-23]$. These non-genetic factors may include variables related to lifestyle (smoking, consumption of antioxidants, physical exercise and body mass index), medical conditions (head injury, metabolic diseases, cancer and inflammatory diseases) and work and environmental related exposure $(\beta$-methylamino- $L$-alanine, viral infections, electromagnetic fields, metals and pesticides) [20, 22]. However, the systematic evidence of the association between environmental risk factors and the occurrence of ALS, besides being very limited, is inadequate or insufficient. We present, in decreasing order of the number of systematic revisions, exposure to agricultural chemical products (i.e., pesticides) [18, 20-25], metals [21-26], 
$\beta$-methylamino-L-alanine $[18,20-22]$ and electromagnetic fields [22].

Comparatively, there is much more evidence on the association with ALS to the exposure to pesticides. In a systematic review of 448 articles on the association between pesticide exposure and human diseases, Mostafalou and Abdollahi [25] found 18 studies, 15 case-control and 3 cohorts assessing the relationship between pesticide exposure and ALS incidence. Ten of the 15 casecontrol studies found an association between exposure to pesticides and the occurrence of ALS, with the odds ratios between 1.1 and 6.9 [27-36]. Kang et al. [24], from a meta-analysis of 19 case-control and 3 cohort studies, also found an association between the risk of ALS and pesticide exposure, (OR 1.44; 95\% CI 1.22-1.70) and with farming (as an occupation, OR 1.42; 95\% CI 1.171.73). They did not, however, find an association between the risk of ALS and exposure to rural environments [24]. In an occupational context and using a metaanalysis of 8 studies [37], Kamel et al. [37] provided evidence of the association between occupational exposure to pesticides and ALS, with OR between 1.4 and 1.8. However, by using data from the Agricultural Health Study and a cohort including 84,739 private pesticide applicators and their spouses, they assessed the association of ALS to specific pesticides and found a statistical association only for organochlorine pesticides (OCP), although they advised caution because of the small number of cases.

In relation to pesticides in particular, those that have been found to have a greater number of statistically significant associations are precisely organochlorine pesticides, followed by polychlorinated biphenyls (PCBs; organic chlorine compound) [37-39]. Su et al. [38] found that the cumulative exposures to 2 OCPs (pentachlorobenzene and cis-chlordane), 2 PCBs (PCB 175 and PCB 202) and 1 organobromine (polybrominated diphenyl ether) were significantly associated with the occurrence of ALS. In Vinceti et al. [39], the increased risk was found only for 2 chemicals, an OCP (the DDT metabolite pp'DDE) and a PCB (PCB congener 28), although the association, besides being statistically very imprecise, was found only in men aged 60 years or more.

With regard to the exposure to metals, systematic evidence includes mostly lead [22, 23, 40,41], but also iron, selenium, manganese $[22,41]$, mercury [41] and aluminium [26]. Occupational exposure to lead has been found to be associated with the occurrence of ALS. According to Wang et al. [40], the risk of developing ALS almost doubled among individuals with a history of

Long-Term Exposure to Environmental

Factors and the Occurrence of ALS exposure to lead, with a pooled odds ratio of 1.81 (95\% CI 1.39-2.36). Santurtún et al. [11] found higher mortality ratios for people older than 65 years in the provinces of northern Spain. There was a significant association between their mortality from motor neuron diseases and higher levels of lead in the air, suggesting that environmental exposures had an important role to play. Two epidemiological surveys have found a higher incidence of ALS in regions with high concentrations of selenium in animal farms [42] and in well water [43]. With regards to iron, Hozumi et al. [44] found ALS patients have higher cerebrospinal fluid iron concentrations. In addition, a very recent meta-analysis including 6 casecontrol studies found an association between elevated serum ferritin levels and ALS [45]. Exposure to mercury may be linked to the aetiology of ALS $[46,47]$. A case in point is the cluster located in a small fishing village next to Lake Michigan, the United States, where the fish had high levels of mercury [48]. The association of risk to ALS and the exposure to manganese is inconsistent. In fact, only 2 studies found a significantly higher concentration of manganese in the cerebrospinal fluid of ALS patients compared to the controls [49-51]. Cicero et al. [41] performed a systematic review of observational case-control studies that assessed the association between metals and neurodegenerative diseases. In the case of ALS, they reviewed 20 studies dated between 1976 and 2017 and concluded that evidence was insufficient to support a causal relationship between exposure to metals and ALS [41].

The aetiology of ALS has been associated with exposure to magnetic fields in some occupational studies. However, the evidence at a general population level is very limited and inconsistent either due to an exposure misclassification or because the association, if it exists, was in fact an indirect consequence of gene-environment interaction. Very recently, Vinceti et al. [52] carried out a population-based case-control study along these lines in 2 regions in Italy (one in the north and the other in the south) and found no association between exposure to magnetic fields from power lines and increased ALS risk.

There is growing evidence that exposure to air pollution is related to neurodegenerative diseases, but little is known about their association with ALS. Using a casecontrol study from 2008 to 2011 in 6 counties surrounding Pittsburgh, the United States, Malek et al. [53] investigated the association between being exposed to air pollution and the occurrence of ALS and found that aromatic solvents significantly elevated the risk of ALS 
(OR 5.03, 95\% CI 1.29-19.53). In fact, the possible influence exposure to solvents has, although interacting with heritability and male sex, had already been found by Gunnarsson et al. [30] through a population-based casecontrol study in central and southern Sweden in 1990. Very recently, through a population-based case-control study conducted in the Netherlands from 2006 to 2011, Seelen et al. [54] investigated the association between long-term exposure to air pollution and the risk of developing ALS. The risk of ALS increased significantly for individuals in the highest quartile of exposure to $\mathrm{PM}_{2.5}$ absorbance (OR 1.67, 95\% CI 1.27-2.18), as well as at concentrations of $\mathrm{NO}_{2}(\mathrm{OR} 1.74,95 \% \mathrm{CI} 1.32-2.30)$ and $\mathrm{NO}_{\mathrm{x}}$ (OR 1.38, 95\% CI 1.07-1.77). These associations, except for $\mathrm{NO}_{\mathrm{x}}$, continued to be statistically significant even after the degree of urbanization had been adjusted for. As is known, environmental noise shares its emission source with air pollutants. However, there is no evidence that the effects of environmental noise on the occurrence of neurodegenerative diseases are independent of those of air pollutants [55]. In addition, no study has been published on the relationship between environmental noise and ALS.

There is also enough evidence (in relative terms), some of it systematic [18,20,22-25], of the existence of spatial clusters of ALS, some of which are associated with environmental factors [18]. Closely related to the existence of spatial clusters, Schwartz et al. [7], found "hot spots" of motor neuron disease mortality (age-adjusted and controlled by annual temperature in a multivariate model), significantly associated with "hot spots" of well water use (at the county level).

In summary, with the exception of pesticides, the systematic evidence for the association between environmental factors and ALS is very limited. In addition, nonsystematic evidence is inconsistent and differs, besides the population and the time period analysed, in terms of the type of the study, the control of the confounding variables and the statistical methods used. In the latter case in particular, the studies also differ in their adjustment of spatial variability.

Our objective here is twofold: (1) to investigate the association between long-term exposures to environmental factors and the occurrence of ALS in Catalonia, Spain and (2) to provide evidence of the existence of spatial clusters of ALS related to these environmental factors. To meet our objectives, we used a population-based nested casecontrol and applied methods in which we controlled both observed and unobserved confounders and we adjusted for spatio-temporal extra variability.

\section{Materials and Methods}

\section{Design}

We carried out a nested case-control study constructed from a retrospective population-based cohort, covering the entire region of Catalonia, Spain. This cohort includes all the patients who were assessed at the Motor Disease Functional Unit (UFMNA) of University Hospital of Bellvitge, L'Hospitalet de Llobregat, Spain and met the "El Escorial" diagnostic criteria for ALS [56].

In our study, cases were subjects diagnosed with ALS between January 1, 2011 and December 31, $2016(n=383,55.6 \%$ of whom were men). We followed the nested case-control studies strategy as the choice for controls. For each case, controls were sampled without replacement at each "failure time" (year of ALS diagnosis in our case) from all the subjects who were still at risk at the time of the failure of the case. In particular, controls were subjects, alive and free of ALS and other neurodegenerative diseases (including Alzheimer, Parkinson's and Parkinsonism), who had had contact with the unit services from 2011 to 2016.

In addition to the year of the ALS diagnosis (for cases) or visit (for controls), the cases were matched with the controls by sex and age at diagnosis (or visit) with a tolerance range of \pm 5 years.

\section{Variables}

Environmental Explanatory Variables

As explanatory variables of interest, we included several environmental variables. It is important to note that we evaluated longterm exposure to these environmental variables. That is to say, a subject, by virtue of residing in a certain place, has been exposed to an average level of various environmental variables throughout the follow-up period (2011-2016). We were interested in the effects of geographical variation that such exposure may have on the occurrence of ALS.

\section{Exposure to Pesticides}

As a proxy to the exposure of pesticides, we considered the distance from the subject's home to the nearest agricultural area. The location of the agricultural areas was obtained from 2 sources: (i) the 2014 soil map of Catalonia, from the Cartographic and Geologic Institute of Catalonia (ICGC) [57] and (ii) the 2015 crop map of Catalonia, elaborated from the data of the single agrarian declaration (DUN) and the geographic information system of agricultural plots (SIGPAC) [58].

Exposure to Air Pollutants Associated with Traffic

We obtained information for 2011-2016 [59] from the 142 monitoring stations in the Catalan Network for Pollution Control and Prevention (XVPCA) located throughout Catalonia on the levels of air pollution to which the cases and controls were exposed (annual mean of daily averages). In particular, we considered particulate matter $\left(\mathrm{PM}_{10}\right.$ coarse particles with a diameter of $10 \mu \mathrm{m}$ or less and $\mathrm{PM}_{2.5}$ fine particles with a diameter of $2.5 \mu \mathrm{m}$ or less), nitrogen oxides $\left(\mathrm{NO}_{2}\right.$ and $\left.\mathrm{NO}\right)$, sulphur dioxide $\left(\mathrm{SO}_{2}\right)$, carbon monoxide $(\mathrm{CO})$, ozone $\left(\mathrm{O}_{3}\right)$, benzene $\left(\mathrm{C}_{6} \mathrm{H}_{6}\right)$, benzopirene (B), lead, arsenic, nickel, cadmium and hydrogen sulphide $\left(\mathrm{H}_{2} \mathrm{~S}\right)$. Not all pollutants were observed at all monitoring stations during the 2011-2016 period. In fact, the median number of monitoring stations in which they were observed was 36 (first quartile 24 monitoring stations, third quartile 67 monitoring stations). $\mathrm{PM}_{10}$ was the pollutant observed in most stations (118 
monitoring stations) and $\mathrm{H}_{2} \mathrm{~S}$ was observed in the fewest (12 monitoring stations).

In addition, as proxies for exposure to air pollution as a result of traffic, we included the distance between the subject's home (either case or control) to the nearest traffic route, as well as exposure to environmental noise.

Traffic routes were classified as (i) streets, (ii) local and county roads and (iii) dual carriageways and motorways. This information was obtained from the 2016 road map of Catalonia, from the ICGC [57]. In order to evaluate the association, as an independent predictor, between the environmental noise and the occurrence of the ALS, we introduced 3 indicators of the same. The information on environmental noise was obtained from all the strategic noise maps for Catalonia available for the period 2007-2012 [60]. Strategic noise maps contain information concerning acoustic noise levels, the estimated number of people located in an area exposed to noise, and the map of acoustic capacity. The maps stratify environmental noise as daytime (7-21 h), evening-time (21-23 h) and night-time (23-7 h) noise. The 2002/49/EC Directive on assessment and management of environmental noise, established the need to make strategic noise maps for agglomerations of more than 250,000 inhabitants [61]. In our case, the maps involved 7 agglomerations containing 20 cities, that is, a total area of $439.56 \mathrm{~km}^{2}$ ( $1.37 \%$ of the total area of Catalonia) and a population of 3,277,232 (43.61\% of the total population of Catalonia).

\section{Other Environmental Variables}

To minimize exposure misclassification, we included 2 additional distances (from the subject's home): (i) to the nearest petrol station and (ii) to the nearest green area. In these last 2 cases, the layers to compute the distances were obtained from the Open Street Map [62] (consulted in December 2016).

\section{Control Variables}

As control variables, we included variables associated with the individual such as sex, age (at diagnosis or visit), year of ALS diagnosis (for cases) and year of visit (for controls). In the database, we also considered variables associated with the subject's family such as indicator of family and family history of disease.

It is possible that some of the ALS risk factors associated with the individual are time-dependent. The effect of some of these time-dependent factors could have been modified by other variables specific to each subject. The problem is that we did not have any information about them and so we included age and sex as proxies for these time-dependent risk factors.

Finally, we included a contextual deprivation index based on the one used in the IneqCities project [63], which was constructed by combining 7 socioeconomic indicators at the census track level where the subject was domiciled. The indicators were obtained from the 2011 Spanish Census of Population and Housing [64].

Since the original cohort consisted of a non-random sample (i.e., individuals who had visited the UFMNA during the study period 2011-2016), we included in the model as an offset the expected numbers of ALS cases in each census tract of each municipality of the study area (i.e., Catalonia).

\section{Construction of the Variables}

Distances to agricultural areas, to traffic routes, to the green areas and to petrol stations were calculated by considering a geographical layer for each case. Further details can be found elsewhere [65].

Long-Term Exposure to Environmental

Factors and the Occurrence of ALS
To estimate the levels of air pollutants to which the cases and controls had been exposed to, we used data from January 1, 2011 to the date of diagnosis (in the cases) and to the first visit (in the controls). Using a joint Bayesian model, we predicted the levels of each of the air pollutants in the locations of the cases and the controls on the date of their diagnosis or the first visit, respectively, with these data. This model allowed us to avoid the problems caused by spatial misalignment. Cases and controls were observed in different spatial locations in which atmospheric pollutants were measured (i.e., they were misaligned). If this problem is not corrected properly (as we did), there will be a complex form of measurement error leading to biased and inconsistent (i.e., asymptotically biased) estimates and erroneous standard errors in the estimates of the parameters. Further details can be found in the study conducted by Barceló et al. [66].

The $\mathrm{DP}_{2}$ method was used to combine the socioeconomic indicators into a single deprivation index [67] (details can be found elsewhere [63]).

The offset (expected numbers of ALS cases in each census tract of each municipality) was calculated annually from 2011 to 2016 with the population of each year, and the incidence rates of ALS observed in each census tract by sex and age were taken as reference. Population data by census tract, age and sex were obtained from the Catalan Institute of Statistics [68] and from the Spanish Census of Population and Housing [64].

We considered male to be the reference category for sex. Age was categorized into quintiles, taking the first as the reference category.

All distance variables were categorized. That is, we allowed a non-linear relationship between the occurrence of ALS and the explanatory variables. To determine all the cut-off points, we performed previous sensitivity analyses. The distances to local and county roads were categorized as follows: less than $50 \mathrm{~m}$, from 50 to $100 \mathrm{~m}$, from 101 to $200 \mathrm{~m}$, and more than $200 \mathrm{~m}$, taking this last category as the reference. In the distance to dual carriageways and motorways, we introduced an additional category: less than $50 \mathrm{~m}$, from 50 to $100 \mathrm{~m}$, from 101 to $200 \mathrm{~m}$, from 201 to $300 \mathrm{~m}$, and more than $300 \mathrm{~m}$ (taking this last category as the reference). The distance to streets was categorized as: less than $25 \mathrm{~m}$, from 25 to $100 \mathrm{~m}$ and more than $100 \mathrm{~m}$ (taking this last category as the reference). The distance to the nearest agricultural area was categorized as: less than $100 \mathrm{~m}$, from 100 to $199 \mathrm{~m}$, from 200 to $299 \mathrm{~m}$ and more than $300 \mathrm{~m}$ (taking this last category as the reference). The distance to the nearest petrol station was categorized as: less than $150 \mathrm{~m}$ (more than $150 \mathrm{~m}$ was the reference category). The distance to the green areas and the 3 variables of environmental noise were categorized in quintils, taking the first quintil as the reference.

In the models, air pollutants were included as a continuous variable (that is, assuming a linear relationship) and categorized in quartiles (i.e., not linearly). In this last case, the first quartile was considered the reference category.

The deprivation index was categorized into quartiles, taking the last quartile (i.e., the one corresponding to the most economic deprivation in the census tracts) as the reference.

\section{Statistical Analysis}

The baseline characteristics of the subjects were summarized by means (and SDs) and medians (and the first and third quartiles) when the variables were quantitative, and by proportions when the variables were qualitative. The differences between the means and 
the medians of the cases and the controls were tested using the Student's $t$ test and the Mann-Whitney U test respectively. The differences in proportions were tested by Pearson's chi-square.

In the multivariate analysis, we specified a generalized linear mixed model with binomial response and a logistic link.

Estimating and Representing the Smoothed Standardized Incidence Rates

First, to evaluate the existence of a geographical pattern in the incidence of ALS, we represented the smoothed standardized incidence rates on a map of the region under study (i.e., Catalonia). To estimate the smoothed standardized incidence rates, we included several random effects in the linear predictor of the logistic model but no observable explanatory variables (although we did include the expected cases in each census tract as an offset).

The most important source of extra variability in a spatial design (as in our case) is "spatial dependence" or clustering. That is to say, areas that are close in space show more similar disease incidence than areas that are not close. In fact, this dependence could be the consequence of unobserved confounders that were spatially distributed (in our case, probably other environmental variables that have been omitted from the model). To capture the spatial dependency, in the regression we included a structured random effect with a Matern structure explicitly constructed through the Stochastic Partial Differential Equation approach [69].

Further, by introducing 2 additional unstructured random effects into the model, we also controlled for the presence of heterogeneity, that is to say, unobserved variables, invariant over time, that are specific to the unit of analysis. In particular, we considered individual heterogeneity associated with each patient, and family heterogeneity, associated with the family to which the patient belonged. Finally, we controlled for temporal trends, as well as temporal heterogeneity, including a random effect structured as a random walk of order 1 [70].

Once we had estimated the model, we calculated the probability of being an ALS case. Using these probabilities, we estimated the cases of ALS in each census tract (by sex and age) and, finally, the smoothed standardized incidence rates. Lastly, we represented these relative risks on a map of Catalonia. Maps at the census track level were obtained from the Spanish Census of Population and Housing [64].

To help evaluate the existence of agglomerations of excess cases (i.e., clusters), we calculated exceedance probabilities that are the probability that the relative risks were greater than 1. Classifying an area as having an elevated risk if the probability was higher than $80 \%$, higher both, sensitivity (probability of detection above $80 \%$ ) and specificity (false detection below 10\%) were achieved [71]. The probabilities were also represented on a map of the study area.

Estimating the Probability of Being a Case Conditioned on the Explanatory Variables

Our hypothesis is that most of the geographical patterns for ALS, if any, could be explained by environmental variables. For this reason, at this stage, we included in the linear predictor of each subject in the logistic model, those variables that might explain the probability of being a case, that is, the environmental variables.

Furthermore, we controlled for observed confounders (including all the covariates indicated above) and unobserved confound- ers (i.e., individual and familiar heterogeneity, spatial dependence and temporal trends). These unobserved confounders were captured by the aforementioned 4 random effects. We also included the expected cases in each census tract as an offset.

As stated above, the explanatory variables (both interest and control variables) were included in the models once categorized, that is, non-linearly. In the case of atmospheric pollutants, however, we allowed them to be included as a continuous variable (i.e., linear). In fact, we first included the categorized pollutants. If the estimators associated with each category were monotonically increasing (or decreasing), we replaced the categorical variable with the continuous.

Given the complexity of our model, we preferred to perform inferences using a Bayesian framework. In particular, we followed the Integrated Nested Laplace Approximation (INLA) approach [72], within a (pure) Bayesian framework.

ALS is a disease with a reduced number of cases in relation to controls. This implies a reduced statistical power of the contrasts used. To increase this, and since we obviously could not increase the sample size, we chose to allow the level of significance (i.e., alpha) to increase, thus reducing the probability of making a Type II error and, therefore, increasing the statistical power.

All analyses were made with the free software $\mathrm{R}$ (version 3.4.1) [73], through the INLA package $[74,72]$. The maps were represented in QGIS (version 2.18) [75].

\section{Results}

We estimated ALS prevalence as 5.09 per 100,000 inhabitants and the crude incidence at 1.12 per 100,000 persons/year (95\% CI 0.85-1.48).

Table 1 shows the basal characteristics of the individuals included in the study. These subjects, $55.6 \%$ of which were men (man/woman ratio of 1.25) had a mean age of 63.2 years (standard deviation of 14.4 years) and a median age of 65 years (first quartile 54 years, third quartile 74 years). Among the cases, the most frequent phenotypes were the classic type (60.6\%), followed at a large distance by the bulbar phenotype (14.3\%) and the respiratory phenotype $(4.3 \%)$. It must be noted that the phenotype in $26.90 \%$ of the cases was unknown.

Regarding the environmental variables, statistically significant differences (both in the means and the medians) were found between the cases and the controls in the distances to agricultural areas, residential streets, petrol stations and green areas; and in the levels of some atmospheric contaminants (sulphur dioxide, ozone and benzene) and metals (lead, nickel and cadmium); and in the levels of arsenic. Regarding the distances, the mean levels were notably much greater than the median levels. This evidences an asymmetric distribution of frequencies for all these variables and indicates that the median must be used as the appropriate statistical summary and 


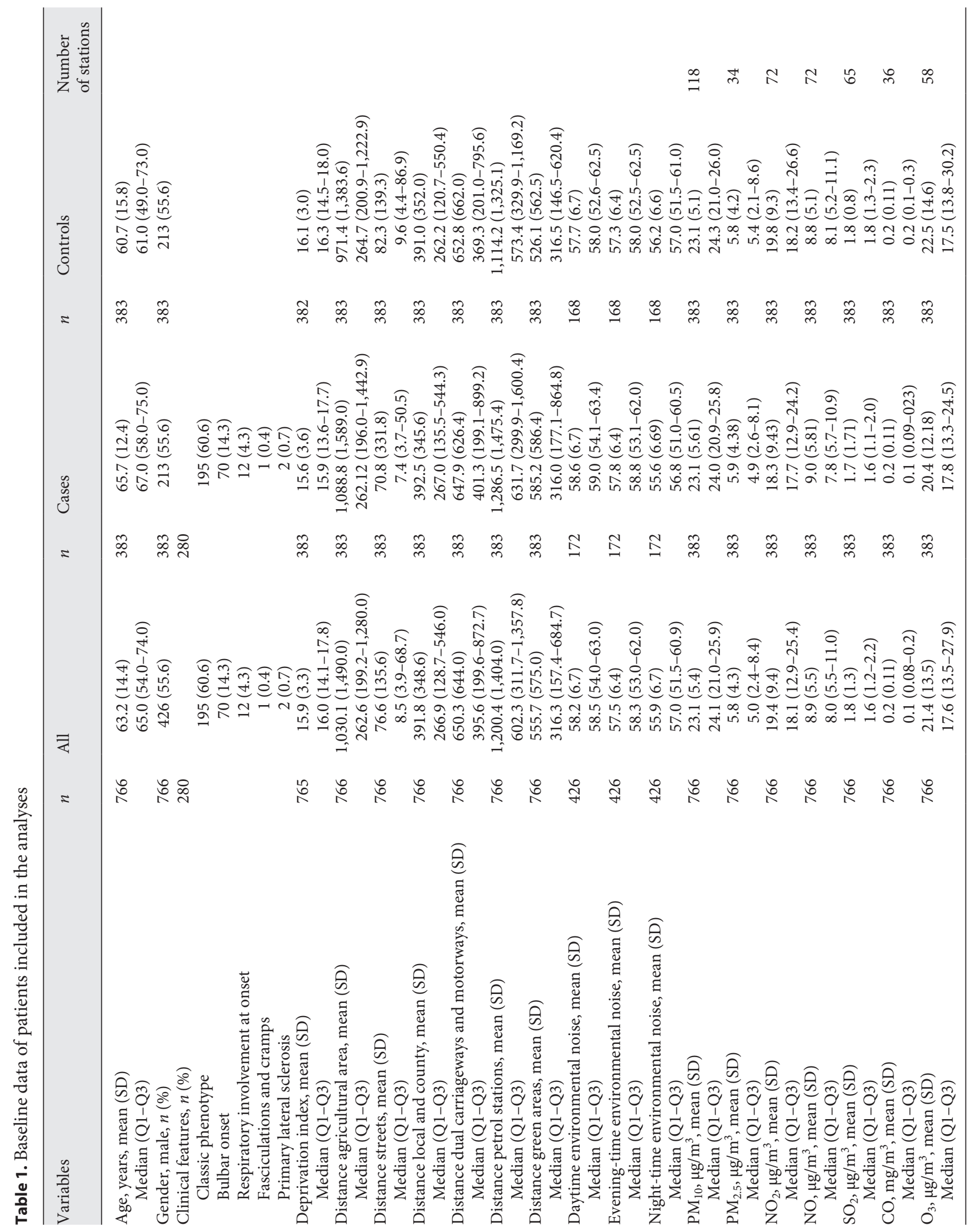




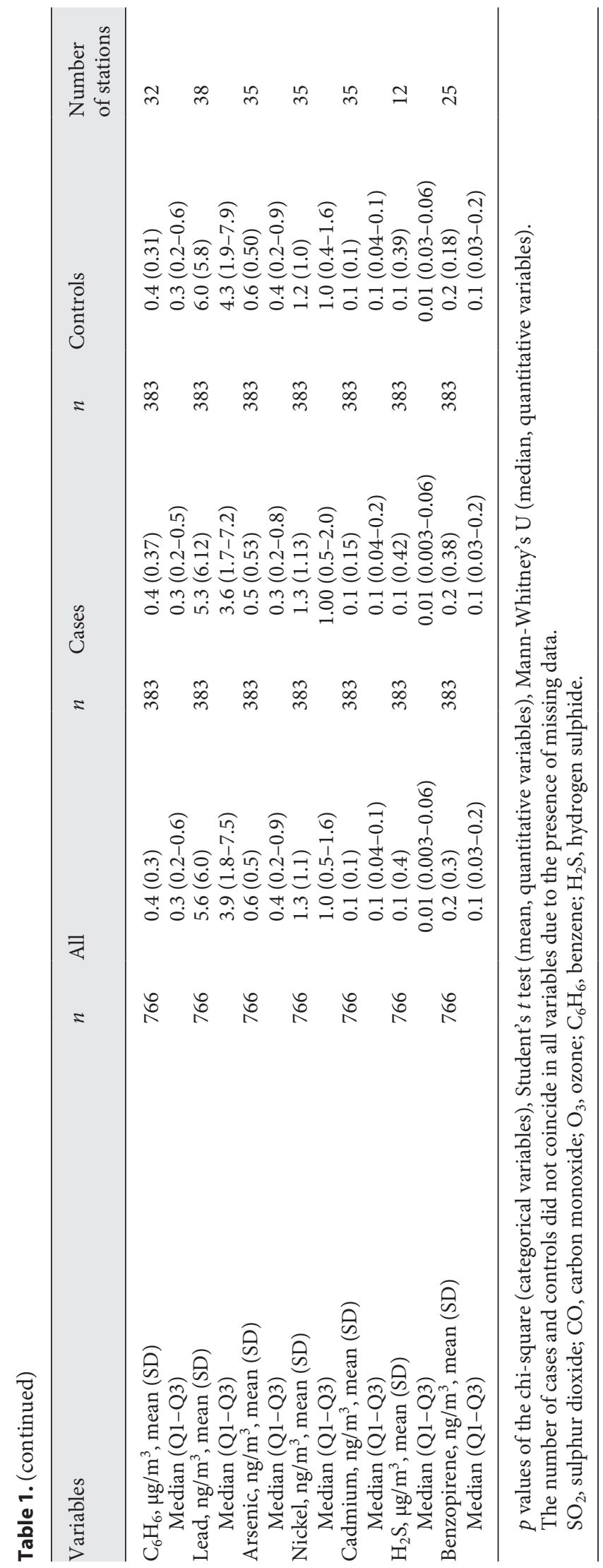

as the Mann-Whitney $U$ test to compare the levels of the variables between the cases and the controls. Thus, even though the median distances of these variables were much smaller in the cases than those in the controls, they were only statistically significant in the case of distances to residential streets. Regarding the levels of atmospheric contaminants, the distribution of frequencies of the variables was also asymmetric, most notably in the cases of benzene and ozone, and slightly less in the case of sulphur dioxide. The levels of sulphur dioxide and benzene to which the controls were exposed were higher than those to which the cases were exposed and they were also statistically significant. The same occurred for cadmium and arsenic, although in the case of the latter, the differences in the median exposure between the cases and the controls were only marginally significant $(p<0.1)$.

Regarding the control variables, statistically significant differences were found between cases and controls in the deprivation index (although slightly less for cases than for controls).

The maps of the smoothed relative risks of the study area and the a posteriori probabilities of such risks being more than 1 are shown in Figures 1a and 2a and in Figures $1 \mathrm{~b}$ and $2 \mathrm{~b}$ respectively. These risks have been calculated from a model than contains neither any explicative variables of interest nor any covariables but does contain random effects and the expected cases in each census tract as an offset. A certain pattern for the risk of incidence of ALS is observed (Figs 1a, 2a) with clusters that coincide with proximity to agricultural areas (Figs 1 b, 2b). In Figure 2, for example, 2 clusters with a high risk of occurrence of ALS can be seen, one in the centre (direction northsouth), corresponding to the counties of Vallès Oriental and Vallès Occidental, and another in the east (direction south-east to north-east), corresponding to the country of Maresme. There also seems to be a moderate-high-risk cluster in the west, corresponding to the county of Baix Llobregat (Fig. 2b).

Table 2 shows the results of the multivariate analysis. Apart from the ORs and their credibility intervals at 95\% (95\% ICr), the probability of the parameter estimator (the $\log (\mathrm{OR})$ as an absolute value being more than 1 (Prob) is also shown (note that it is unilateral and so does not necessarily have to coincide with the ICr in all the cases). Unlike the $p$ value in a usual environment, this probability allows us to make inferences about the possible association. For the sake of simplicity, only the results corresponding to the variables in which the Prob of the associated coefficient (when it was included lin- 
Fig. 1. a Map of the smoothed relative risks over the study region (Catalonia). b Map over Catalonia of the posterior probability that the smoothed relative risks were greater than unity (PRP). Model with heterogeneity and spatial adjustment only (besides the expected cases in the census tract as an offset), without explanatory variables [1].

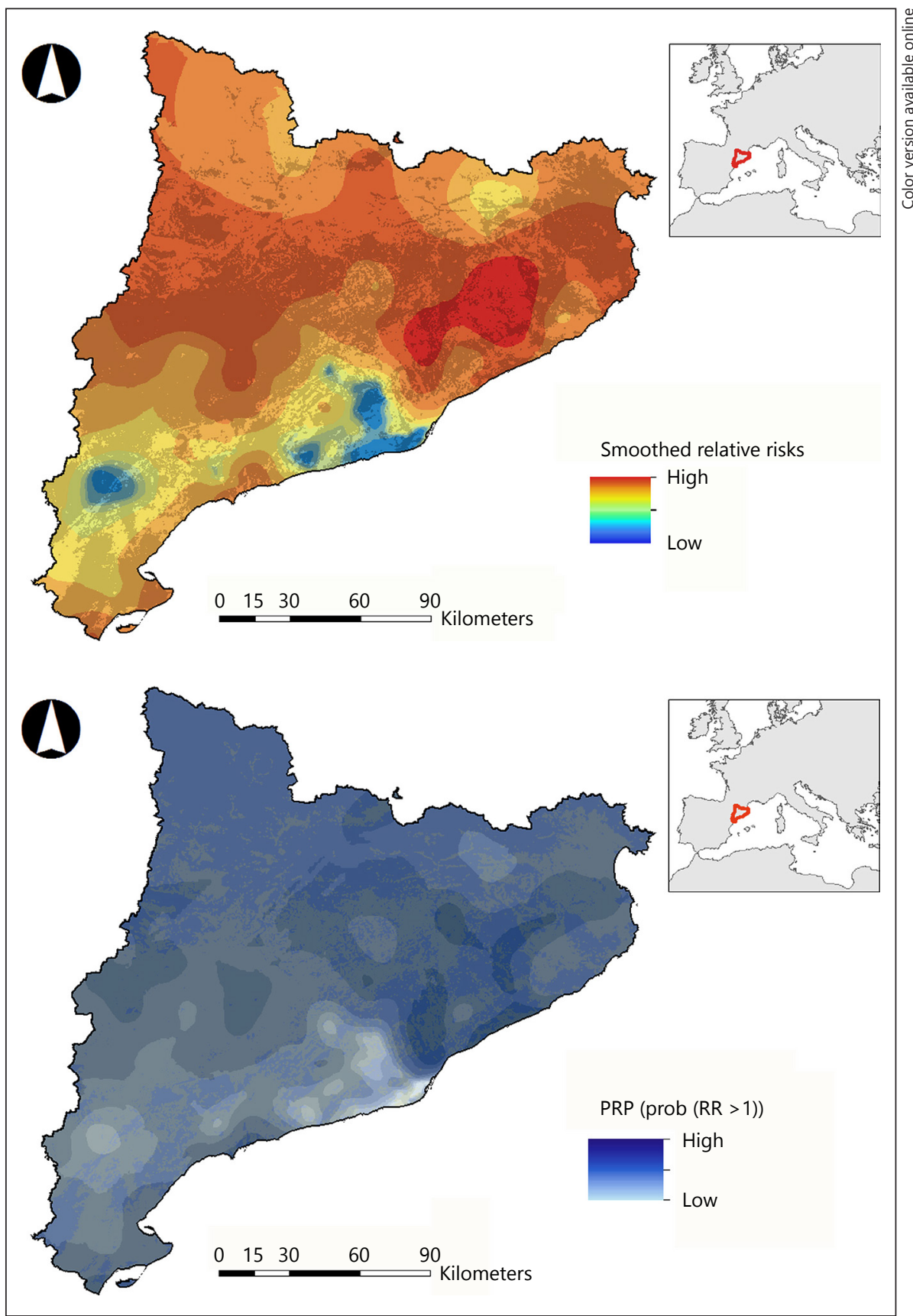

early in the model), or of at least one of the coefficients associated with its categories (when it was included categorically) being more than 0.80 are shown. An association is shown to exist between the occurrence of ALS and the distance from the residence of the subject to the nearest agricultural area. Patients who lived less than $100 \mathrm{~m}$ from an agricultural area were at greater risk of being affected by ALS than those who lived further away (OR 5.483; 95\% ICr 1.279-25.23, Prob 98.93\%).
The same occurred, albeit less markedly, for patients who lived between 100 and $199 \mathrm{~m}$ from an agricultural zone (OR 1.559; 95\% ICr 0.809-3.012; Prob 90.75\%). Moreover, living between 25 and $100 \mathrm{~m}$ from the nearest road increased the risk of being affected by ALS compared with living more than $100 \mathrm{~m}$ from it (OR 1.364; 95\% ICr 0.885-2.104; Prob 91.99\%). An association was also found between some atmospheric contaminants and the incidence of ALS. More specifically, 
Fig. 2. a Map of the smoothed relative risks over the Metropolitan Area of Barcelona. b Map over the Metropolitan Area of Barcelona of the posterior probability that the smoothed relative risks were greater than unity (PRP). Model with heterogeneity and spatial adjustment only (besides the expected cases in the census tract as an offset), without explanatory variables [1].

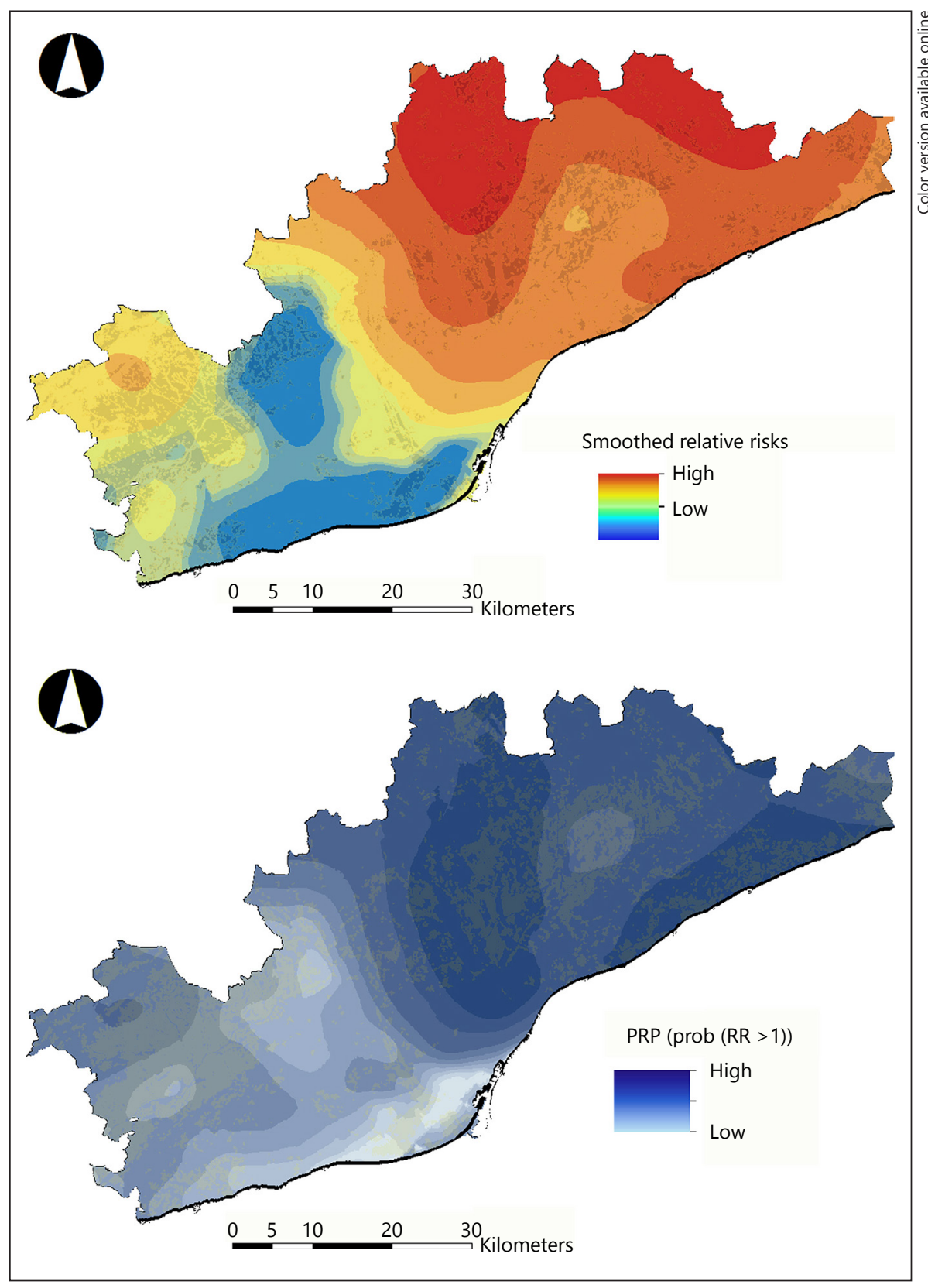

a non-linear and statistically significant relation was found to exist in the case of $\mathrm{NO}_{2}$, which presented an increasing gradient for the OR (OR quartile 2 1.872; 95\% ICr 1.487-2.023; Prob 99.73\%; OR quartile 32.047 ; 95\% ICr 1.698-2.898; Prob 99.73\%; OR quartile 42.703 ; 95\% ICr 1.265-3.255; Prob 99.84\%), and in the case of $\mathrm{NO}$, although in this case only the fourth quartile was statistically significant (and only at $90 \%$; OR quartile 4 1.321; 95\% ICr 0.530-3.340; Prob 92.71\%). A linear association was found between cadmium and the occurrence of ALS (OR 1.332; 95\% ICr 0.729-13.71; Prob
92.62\%) and between benzopireno and ALS, although in this case, the association was not statistically significant (OR 1.122; 95\% ICr 0.359-4.140; Prob 85.39\%). Last, exposure to ozone was found to have a protector effect on the incidence of ALS (OR 0.973; 95\% ICr 0.949-1.061; Prob 92.67\%).

Finally, with the idea of observing a possible synergy between living near agricultural areas (less than $100 \mathrm{~m}$ ) and other environmental variables, the interactions between living less than $100 \mathrm{~m}$ from agricultural areas and living near traffic routes were introduced into the model, 
Table 2. Association between environmental variables and occurrence of ALS, Catalonia 2011-2016

\begin{tabular}{|c|c|c|}
\hline Variables & OR (95\% credibility interval) & $\operatorname{Prob}([\log (\mathrm{OR})])>0$ \\
\hline \multicolumn{3}{|c|}{ Distance agricultural areas $(>300 \mathrm{~m}), \mathrm{m}$} \\
\hline$<100$ & $5.483(1.279-25.23)$ & 0.9893 \\
\hline $100-199$ & $1.559(0.809-3.012)$ & 0.9075 \\
\hline $200-299$ & $0.910(0.492-1.672)$ & 0.6197 \\
\hline \multicolumn{3}{|l|}{ Distance streets (>100 m), m } \\
\hline$<25$ & $1.615(0.692-3.778)$ & 0.8658 \\
\hline $25-100$ & $1.364(0.885-2.104)$ & 0.9199 \\
\hline \multicolumn{3}{|c|}{ Distance local and county (>200 m), m } \\
\hline$<50$ & $0.514(0.211-1.198)$ & 0.7666 \\
\hline $50-100$ & $1.394(0.736-2.636)$ & 0.8459 \\
\hline $101-200$ & $1.196(0.709-2.014)$ & 0.7492 \\
\hline \multicolumn{3}{|c|}{ Distance dual carriageways and higways (>300 m), m } \\
\hline$<50$ & $0.754(0.208-2.670)$ & 0.6659 \\
\hline $50-100$ & $1.285(0.588-2.800)$ & 0.7357 \\
\hline $101-200$ & $0.665(0.368-1.191)$ & 0.8152 \\
\hline $200-300$ & $0.963(0.537-1.720)$ & 0.5516 \\
\hline Distance petrol stations $(>150 \mathrm{~m})$ & $0.502(0236-1.044)$ & 0.8674 \\
\hline \multicolumn{3}{|l|}{ Distance green areas (quintile 1) } \\
\hline Quintile 2 & $0.910(0.481-1.715)$ & 0.6145 \\
\hline Quintile 3 & $1.283(0.686-2.403)$ & 0.7814 \\
\hline Quintile 4 & $0.834(0.437-1.593)$ & 0.7058 \\
\hline Quintile 5 & $1.381(0.662-2.910)$ & 0.8034 \\
\hline \multicolumn{3}{|c|}{ Daytime environmental noise (quintile 1) } \\
\hline Quintile 2 & $4.531(0.290-106.8)$ & 0.8447 \\
\hline Quintile 3 & $0.528(0.009-36.06)$ & 0.6255 \\
\hline Quintile 4 & $0.085(0.001-6.692)$ & 0.8693 \\
\hline Quintile 5 & $0.386(0.004-37.10)$ & 0.6635 \\
\hline \multicolumn{3}{|c|}{ Evening-time environmental noise (quintile 1 ) } \\
\hline Quintile 2 & $0.443(0.018-7.500)$ & 0.6931 \\
\hline Quintile 3 & $4.956(0.055-380.1)$ & 0.7632 \\
\hline Quintile 4 & $29.14(0.294-2,587)$ & 0.8261 \\
\hline Quintile 5 & $13.12(0.104-1,499)$ & 0.8538 \\
\hline \multicolumn{3}{|c|}{ Night-time environmental noise (quintile 1) } \\
\hline Quintile 2 & $1.437(0.438-4.539)$ & 0.7305 \\
\hline Quintile 3 & $0.886(0.199-3.865)$ & 0.5631 \\
\hline Quintile 4 & $0.817(0.149-4.381)$ & 0.5930 \\
\hline Quintile 5 & $0.439(0.065-2.926)$ & 0.8031 \\
\hline \multicolumn{3}{|l|}{$\mathrm{NO}_{2}$ (quartile 1) } \\
\hline Quartile 2 & $1.872(1.487-2.023)$ & 0.9973 \\
\hline Quartile 3 & $2.047(1.698-2.898)$ & 0.9973 \\
\hline Quartile 4 & $2.703(1.265-3.255)$ & 0.9984 \\
\hline \multicolumn{3}{|l|}{ NO (quartile 1) } \\
\hline Quartile 2 & $0.515(0.140-1.958)$ & 0.7216 \\
\hline Quartile 3 & $0.329(0.074-1.482)$ & 0.8394 \\
\hline Quartile 4 & $1.321(0.530-3.340)$ & 0.9271 \\
\hline Benzopirene & $1.122(0.359-4.140)$ & 0.8539 \\
\hline Cadmium & $1.332(0.729-13.71)$ & 0.9262 \\
\hline Ozone & $0.973(0.949-1.061)$ & 0.9267 \\
\hline
\end{tabular}

Adjusted by sex, age, year of diagnosis, family history of disease, indicator of family in the database, contextual deprivation index.

Prob (abs $[\log (\mathrm{OR})]>0$ ) higher than 0.95. Prob $($ abs $[\log (\mathrm{OR})]>0)$ higher than 0.90 .

Long-Term Exposure to Environmental Factors and the Occurrence of ALS
Neuroepidemiology 2018;51:33-49 DOI: 10.1159/000489664 
as well as living in areas with high levels of atmospheric contamination. Only the interactions with the fourth quartiles of $\mathrm{NO}_{2}$ (OR 1.094, Prob 98.62\%) and $\mathrm{NO}$ (OR 1.124, Prob 98.70\%) were statistically significant. Furthermore, the fourth quartile of benzopirene and living less than $100 \mathrm{~m}$ from a dual carriageway or a motorway, even when they were risk factors and where the probability of the odds ratio being more than the unit was over $85 \%$ in both cases, were not statistically significant. It must be pointed out that unlike the main effect, the interaction between living less than $100 \mathrm{~m}$ from agricultural areas and in an area with high levels of ozone (located in the fourth quartile) was a risk factor (OR 2.484, Prob 88, 22\%).

\section{Discussion}

We found a certain geographical pattern for the risk of ALS occurrence. In addition, 3 clusters can be observed, 2 of them with a high risk of occurrence of ALS one in the centre of the study region (north-south direction) and another in the east (direction southwest-northeast), and the third one with a moderate-high risk in the west.

As mentioned above, there is enough evidence, including some systematic reviews [18, 20, 22-25], of the existence of spatial clusters of ALS. However, only in some of them have environmental factors been suggested as a possible explanation for their occurrence $[14,48$, 76-82]. This is particularly notable for exposure to metals $[48,77,80,81]$ and to agricultural chemicals [7881], although exposure to industrial toxins [77] and to paper paste and water treatment plants [82] also appears. As early as 1977, Kilness and Hichberg [76] attributed selenium exposure over a period of 10 years to the small cluster (4 ALS cases that lived within $15 \mathrm{~km}$ of each other) that they identified in west-central South Dakota, USA. Almost 30 years ago, Sienko et al. [48] detected a cluster in a small fishing village next to Lake Michigan, USA, which is probably associated with a high intake of mercury. In addition to genetics, among the factors to which Sabel et al. [80] attribute the existence of 2 significant clusters in south-eastern Finland (one at the time of death and other at the time of birth, of those who died between 1985 and 1995) and another in south-central Finland (at the time of death) is the exposure to heavy metals and agricultural chemicals. Similarly, Uccelli et al. [81] identified 16 clusters with significant high relative risk of ALS mortality (12 of them included in a single municipality) in all Italian municipalities in the period 1980-2001 and suggest, in addition to genetics, that agricultural chemicals and lead could be involved. However, very recently, Tesauro et al. [14], investigated an ALS cluster reported in the Briga area (in the province of Novara, northern Italy), known for its high level of heavy metal contamination, which has had a serious impact on soil, surface water and groundwater, but they could not confirm an excess of ALS incidence.

Our results could be in line with the findings of those studies, particularly with those that attribute in some way to the exposure to agricultural chemicals $[80,81]$. In this sense, all the clusters we identified correspond to areas of intensive agriculture. In our case, the high-risk clusters, besides corresponding to agricultural areas, also correspond to significant road infrastructures that carry a high density of traffic. In fact, our hypothesis could be corroborated by the results of the interactions of those living less than $100 \mathrm{~m}$ from an agricultural area and high levels of nitrogen oxides (significant at 95\%), benzopyrene and ozone (significant at $85 \%$ ) as well as for those living less than $100 \mathrm{~m}$ away from dual carriageways and motorways (significant at $85 \%$ ).

The results of the multivariate model suggest that these clusters could be related to some of the environmental variables. Specifically, living near an agricultural area increased the risk of ALS occurrence (especially for less than $100 \mathrm{~m}$ and in a smaller magnitude between 100 and $199 \mathrm{~m}$ ). In addition, air pollution resulting from traffic could also be related to the occurrence of ALS. Thus, besides living between 25 and $100 \mathrm{~m}$ from a residential street, high $\mathrm{NO}_{2}$ and $\mathrm{NO}$ concentrations in the air where the subject resides, indicated a greater risk of occurrence of ALS. We also found a statistically significant association between exposure to ozone and the occurrence of ALS. In addition, we found a linear association between benzopyrene levels in the air and the occurrence of ALS (albeit not statistically significant). Benzopyrene belongs to the chemical class of polycyclic aromatic hydrocarbons, ubiquitous compounds of which one of the sources is motor vehicle exhaust fumes. The statistically significant associations found for cadmium and, to a lesser extent, benzopyrene (another source for this is the chemical industry), could suggest some relationship between emissions from industrial activities and the occurrence of ALS. In fact, cadmium emissions come mainly from industrial processes using combustion chiefly derived from inorganic chemical compounds [83]. 
We considered the distance (from the subject's home) to the agricultural area as a proxy for pesticide exposure. In fact, and as can be seen, we followed a strategy similar to that of the studies suggesting agricultural chemicals as an explanation for the high-risk clusters of ALS occurrence $[80,81]$, as well as the strategy used by Das et al. [84], in a case-control study carried out from 2008 to 2011 in India. Here, they found (in addition to electrical injury - OR 1.62-; and smoking - OR 1.88-) that not only exposure to pesticides (OR 1.61) but also living in a rural habitat (OR 1.99) were the associated factors in the occurrence of ALS. They argue that rural people are exposed to insecticides and pesticides during their occupational work in agriculture and also when drinking water which, in their study region (east of India), may sometimes be contaminated with insecticides and pesticides [84]. Assuming that the distance to agricultural areas was a good proxy for exposure to pesticides, our results would be in line with those where associations between exposure to pesticides and the occurrence of ALS have been made [27-36, 38].

Although there are only a few studies that relate exposure to air pollutants as a result of traffic and the occurrence of ALS [32, 53, 54], our results are similar. Seelen et al. [54] in particular, find that, as in our case, once adjusted for possible confounders, the risk of ALS is significantly higher for subjects with high levels of exposure to $\mathrm{NO}_{2}$. Unlike them, however, we did not find an association between $\mathrm{PM}_{2.5}$ absorbance concentrations and the occurrence of ALS. As in Vinceti et al. [39], neither did we find a significant association with ALS and the polycyclic aromatic hydrocarbon benzopyrene.

We do not have an explanation for the protective effect found for ozone exposure. One possibility is that antagonistic interactions occur between ozone and nitrogen dioxide [85]. In addition, ozone levels tend to be lower in urban areas than in suburban and rural areas. This is because it is a secondary pollutant that does not appear immediately. There is a gap between the emission of precursors and its formation. Furthermore, winds can carry polluted air masses out of the cities and direct them towards the peripheral or rural areas. On the other hand, the highest concentrations of ozone do not occur near the emission source but rather a certain distance away from it because the ozone that forms in the proximities of the focus reacts with the existing nitrogen monoxide and destroys itself in the proximity of the source [86]. Therefore, it is likely that the areas with the most air pollution as a result of traffic, and those with a

Long-Term Exposure to Environmental Factors and the Occurrence of ALS higher risk of occurrence of ALS, are those with a lower concentration of ozone. The results from the interactions of living less than $100 \mathrm{~m}$ from an agricultural area and high levels of ozone (significant at $85 \%$ ) could be indicative of this fact. High levels of ozone would occur in suburban or rural areas and, therefore, close to the agrarian zones. In those areas, we find that interaction is a risk factor. However, in our case, most ALS cases were collected in urban areas. For this reason, the interaction was significant only at $85 \%$.

In line with the systematic review by Tzivian et al. [55], we found that, once air pollutants have been controlled, none of the indicators of environmental noise is related to the occurrence of ALS either directly (levels of the contaminant) or indirectly (through the proxies of distance to roads). However, more studies are needed to determine if the role of environmental noise can be independent to that of air pollutants.

Our study might have some limitations. First, although we included an offset in the model to control for these effects, the original cohort consisted of a non-random sample. However, it would seem that the sample we used was, in fact, quite representative. First, we estimated a prevalence of ALS at 5.09 per 100,000 inhabitants, (i.e., within the range indicated in the literature $[5-5.4][9,14])$, and a crude incidence at 1.12 per 100,000 person/years $(95 \%$ CI 0.85-1.48), an interval containing the incidence estimated by Pradas et al. [12], for Catalonia (1.4 per 100,000 inhabitants). Second, the male/female ratio in the incidence in our sample was only slightly less than that reported in the literature $[15,10,12]$ (1.25 vs. $1.3-1.5$ respectively). The mean age of the cases was 63.22 years and the median age was 65 years. These figures corresponded to the mean age at onset, which ranges from 58 to 63 years for the sporadic form and 40 to 60 years for the familial form [9].

Third, we did not know the family history of the controls and, therefore, we did not know if they had a family history of ALS in a first or second-degree blood relative. However, much of this limitation is avoided by the strategy we followed when choosing the controls. The controls were subjects, alive and free of ALS and other neurodegenerative diseases at each failure time and, therefore, they were still at risk at the time of the failure of the case, no matter their family history.

Fourth, we used proxies to approximate exposure to environmental variables (especially distances). We were not able to determine to which particular variable or to what amount of environmental variable the subject was exposed to. We believe, however, that we controlled part 
of this exposure misclassification by including a structured random effect that captured spatial dependence. In fact, this dependence is the consequence of unobserved confounders that were spatially distributed.

Fifth, our study was unicentric, so the results could not be extrapolated to other populations.

Our sixth limitation is that the variability in the evolutionary moment of the disease makes the results heterogeneous and limits their comparison.

Finally, as in any Bayesian analysis, the choice of the prior distributions of model parameters (i.e., priors) may have had a considerable impact on the results. However, we used priors that penalize the complexity (PC priors) [87] and which have been found to be very robust. Furthermore, we performed sensitivity analyses to assess how the priors on the hyperparametres influenced the estimation results. First, by increasing the precision (lowering the variance) and second, by testing other priors, that is, those used by default in R INLA (log gamma) with different shapes and inverse-scales: uniform and centred half-normal. In all cases, the PC priors provided better results.

We believe that these limitations are offset by the strengths of our study. In particular, we highlight three. First, we used a nested case-control constructed from a population-based retrospective cohort. The fact that it is population-based could counteract the limitation of non-generalization. Our second strength lies in the fact that, in addition to controlling for the observed confounding, we used random effects to control for unobserved confounding. Our third strength is that we adjusted for the spatial extra variability inherent in all spatial design.

\section{Conclusion}

We have found that some environmental factors could be associated with the occurrence of ALS. Specifically, exposure to pesticides, which we approximated by proximity to agricultural areas, as well as to certain pollutants (particularly those whose source is traffic, most likely diesel vehicles, i.e., exposure to nitrogen oxides), could be independent predictors of that occurrence. But, in addition, both the high-risk clusters that we have found, as well as the significance of the interactions in the multivariate models, allow us to hypothesize that exposure to high levels of air pollutants as a result of traffic could increase the risk associated with living close to agricultural areas.

\section{Acknowledgements}

We thank Diego Varga, GRECS, University of Girona, for his very valuable help in applying the methods of the geographical information system. We also appreciate the comments of the attendees at the European Network for Cure of ALS, ENCALS, meeting 2017, held in Ljubliana, Slovenia, on May 18-20, 2017, and at the 29th Annual Scientific Conference of the International Society of Environmental Epidemiology, ISEE 2017', held on September 24-28, 2017, in Sydney, Australia, where a preliminary version of this work was presented. The usual disclaimer applies. We appreciate the comments of 2 anonymous reviewers of a previous version of this work who, without doubt, helped us to improve our work.

\section{Ethics Statement}

The data for this study came from an anonymised clinical administrative database and only the lead researcher, where necessary, had access to the identity of each individual. This study has also been revised and approved by the CEIC of the University Hospital of Bellvitge.

\section{Disclosure Statement}

The manuscript is an original contribution that has not been published before, whole or in part, in any format, including electronically. All authors will disclose any actual or potential conflict of interest including any financial, personal or other relationships with other people or organizations that could inappropriately influence or be perceived to influence their work, within 3 years of beginning the submitted work.

\section{Data availability}

Due to the restrictions on the transfer of data to third parties, both ethical (in accordance with the protocol approved by the Clinical Research Ethics Committee (CEIC) of the University Hospital of Bellvitge) and legal (the provisions of the Spanish Law on Data Protection, Fundamental Law 15/1999 of December 13 on the Protection of Personal Data, article 7.3), data (appropriately anonymised) will be available to all interested researchers upon request to Mònica Povedano (30058mpp@ gmail.com).

\section{Funding Source}

This work was partly funded by the University of Girona (MPCUdG2016, TRANSFER2016/24 and GDRCompetUdG2017) and by an unrestricted grant from Grupo Temporing. Neither the University of Girona nor the Grupo Temporing participated in the design of the study, collection, analysis and interpretation of data or in writing the manuscript. 


\section{References}

1 Boylan K: Familial amyotrophic lateral sclerosis. Neurol Clin 2015;33:807-830.

-2 Boillée S, Vande Velde C, Cleveland DW: ALS: a disease of motor neurons and their nonneuronal neighbors. Neuron 2006;52:39-59.

-3 Mancuso R, Navarro X: Amyotrophic lateral sclerosis: current perspectives from basic research to the clínic. Prog Neurobiol 2015;133: $1-26$.

-4 Kiernan MC, Vucic S, Cheah BC, Turner MR, Eisen A, Hardiman O, Burrell JR, Zoing MC: Amyotrophic lateral sclerosis. Lancet 2011; 377:942-955.

5 Chiò A, Logroscino G, Traynor BJ, Collins J, Simeone JC, Goldstein LA, White LA: Global epidemiology of amyotrophic lateral sclerosis: a systematic review of the published literature. Neuroepidemiology 2013;41:118130.

6 Wolf J, Safer A, Wöhrle JC, Palm F, Nix WA, Maschke M, Grau AJ: Variability and prognostic relevance of different phenotypes in amyotrophic lateral sclerosis - data from a population-based registry. J Neurol Sci 2014; 345:164-167.

7 Schwartz GG, Rundquist BC, Simon IJ, Swartz SE: Geographic distributions of motor neuron disease mortality and well water use in U.S. counties. Amyotroph Lateral Scler Frontotemporal Degener 2017;18:279-283.

8 Al-Chalabi A, Hardiman O: The epidemiology of ALS: a conspiracy of genes, environment and time. Nat Rev Neurol 2013;9:617628.

-9 Belbasis L, Bellou V, Evangelou E: Environmental risk factors and amyotrophic lateral sclerosis: an umbrella review and critical assessment of current evidence from systematic reviews and meta-analyses of observational studies. Neuroepidemiology 2016;46: 96-105.

10 Marin B, Boumédiene F, Logroscino G, Couratier $\mathrm{P}$, Babron MC, Leutenegger AL, Copetti M, Preux PM, Beghi E. Variation in worldwide incidence of amyotrophic lateral sclerosis: a meta-analysis. Int J Epidemiol 2017;46: 57-74.

-11 Santurtún A, Villar A, Delgado-Alvarado M, Riancho J. Trends in motor neuron disease: association with latitude and air lead levels in Spain. Neurol Sci 2016;37:1271-1275.

12 Pradas J, Puig T, Rojas-García R, Viguera ML, Gich I, Logroscino G; ALS-CAT Group. Amyotrophic lateral sclerosis in catalonia: a population based study. Amyotroph Lateral Scler Frontotemporal Degener 2013;14:273283.

13 Doi Y, Atsuta N, Sobue G, Morita M, Nakano I: Prevalence and incidence of amyotrophic lateral sclerosis in Japan. J Epidemiol 2014;24: 494-499.

14 Tesauro M, Consonni M, Filippini T, Mazzini L, Pisano F, Chiò A, Esposito A, Vinceti M: Incidence of amyotrophic lateral sclerosis in the province of Novara, Italy, and possible role of environmental pollution. Amyotroph Lateral Scler Frontotemporal Degener 2017; 18:284-290.

15 Mehta P, Kaye W, Bryan L, Larson T, Copeland T, Wu J, Muravov O, Horton K: Prevalence of amyotrophic lateral sclerosis - United States, 2012-2013. MMWR Surveill Summ 2016;65:1-12.

16 Cima V, Logroscino G, D’Ascenzo C, Palmieri A, Volpe M, Briani C, Pegoraro E, Angelini C, Soraru G: Epidemiology of ALS in Padova district, Italy, from 1992 to 2005. Eur J Neurol 2009;16:920-924

17 Bonaparte JP, Grant IA, Benstead TJ, Murray TJ, Smith M: ALS incidence in Nova Scotia over a 20-year-period: a prospective study. Can J Neurol Sci 2007;34:69-73.

18 Caller TA, Field NC, Chipman JW, Shi X, Harris BT, Stommel EW: Spatial clustering of amyotrophic lateral sclerosis and the potential role of BMAA. Amyotroph Lateral Scler 2012;13:25-32.

19 Caller TA, Chipman JW, Field NC, Stommel EW: Spatial analysis of amyotrophic lateral sclerosis in Northern New England, USA, 1997-2009. Muscle Nerve 2013;48: 235-241.

20 Trojsi F, Monsurrò MR, Tedeschi G: Exposure to environmental toxicants and pathogenesis of amyotrophic lateral sclerosis: state of the art and research perspectives. Int J Mol Sci 2013;14:15286-15311.

21 Modgil S, Lahiri DK, Sharma VL, Anand A: Role of early life exposure and environment on neurodegeneration: implications on brain disorders. Transl Neurodegener 2014;29:3-9.

22 Ingre C, Roos PM, Piehl F, Kamel F, Fang F: Risk factors for amyotrophic lateral sclerosis. Clin Epidemiol 2015;7:181-193.

23 Oskarsson B, Horton DK, Mitsumoto H: Potential environmental factors in amyotrophic lateral sclerosis. Neurol Clin 2015;33:877888.

24 Kang H, Cha ES, Choi GJ, Lee WJ: Amyotrophic lateral sclerosis and agricultural environments: a systematic review. J Korean Med Sci 2014;29:1610-1617.

25 Mostafalou S, Abdollahi M: Pesticides: an update of human exposure and toxicity. Arch Toxicol 2017;91:549-599.

26 Maya S, Prakash T, Madhu KD, Goli D: Multifaceted effects of aluminium in neurodegenerative diseases: a review. Biomed Pharmacother 2016;83:746-754.

27 Deapen DM, Henderson BE: A case-control study of amyotrophic lateral sclerosis. Am J Epidemiol 1986;123:790-799.

28 Savettieri G, Salemi G, Arcara A, Cassata M, Castiglione MG, Fierro B: A case-control study of amyotrophic lateral sclerosis. Neuroepidemiology 1991;10:242-245.

29 Chancellor AM, Slattery JM, Fraser H, Warlow CP: Risk factors for motor neuron disease: a case-control study based on patients from the Scottish motor neuron disease regis- ter. J Neurol Neurosurg Psychiatry 1993;56: $1200-1206$

30 Gunnarsson LG, Bodin L, Soderfeldt B, Axelson $\mathrm{O}$ : A case-control study of motor neurone disease: its relation to heritability, and occupational exposures, particularly to solvents. Br J Ind Med 1992;49:791-798.

- 31 McGuire V, Longstreth WT Jr, Nelson LM, Koepsell TD, Checkoway H, Morgan MS, van Belle G: Occupational exposures and amyotrophic lateral sclerosis. A population-based case-control study. Am J Epidemiol 1997;145: 1076-1088

32 Qureshi MM, Hayden D, Urbinelli L, Ferrante K, Newhall K, Myers D, Hilgenberg S, Smart R, Brown RH, Cudkowicz ME: Analysis of factors that modify susceptibility and rate of progression in amyotrophic lateral sclerosis (ALS). Amyotroph Lateral Scler 2006;7:173-182.

-33 Furby A, Beauvais K, Kolev I, Rivain JG, Sebille V: Rural environment and risk factors of amyotrophic lateral sclerosis: a case-control study. J Neurol 2010;257:792-798.

34 Bonvicini F, Marcello N, Mandrioli J, Pietrini V, Vinceti M: Exposure to pesticides and risk of amyotrophic lateral sclerosis: a populationbased case-control study. Ann Ist Super Sanita 2010;46:284-287.

35 Malek AM, Barchowsky A, Bowser R, Heiman-Patterson T, Lacomis D, Rana S, Youk A, Stickler D, Lackland DT, Talbott EO: Environmental and occupational risk factors for amyotrophic lateral sclerosis: a case-control study. Neurodegener Dis 2014;14:3138.

36 Yu Y, Su F, Callaghan BC, Goutman SA, Batterman SA, Feldman EL: Environmental risk factors and amyotrophic lateral sclerosis (ALS): a case-control study of ALS in Michigan. PLos One 2014;9:e101186.

-37 Kamel F, Umbach DM, Bedlack RS, Richards M, Watson M, Alavanja MC, Blair A, Hoppin JA, Schmidt S, Sandler DP: Pesticide exposure and amyotrophic lateral sclerosis. Neurotoxicology 2012;33:457-462.

-38 Su FC, Goutman SA, Chernyak S, Mukherjee B, Callaghan BC, Batterman S, Feldman EL: Association of environmental toxins with amyotrophic lateral sclerosis. JAMA Neurol 2016;73:803-811.

39 Vinceti M, Violi F, Tzatzarakis M, Mandrioli J, Malagoli C, Hatch EE, Fini N, Fasano A, Rakitskii VN, Kalantzi OI, Tsatsakis A: Pesticides, polychlorinated biphenyls and polycyclic aromatic hydrocarbons in cerebrospinal fluid of amyotrophic lateral sclerosis patients: a case-control study. Environ Res 2017;155: 261-267.

40 Wang MD, Gomes J, Cashman NR, Little J, Krewski D: A meta-analysis of observational studies of the association between chronic occupational exposure to lead and amyotrophic lateral sclerosis. J Occup Environ Med 2014; 56:1235-1242.
Long-Term Exposure to Environmental Factors and the Occurrence of ALS
Neuroepidemiology 2018;51:33-49 DOI: $10.1159 / 000489664$ 
-41 Cicero CE, Mostile G, Vasta R, Rapisarda V, Signorelli SS, Ferrante M, Zappia M, Nicoletti A: Metals and neurodegenerative diseases. A systematic review. Environ Res 2017;159: 82-94.

-42 Kilness AW, Hichberg FH: Amyotrophic lateral sclerosis in a high selenium environment. JAMA 1977;237:2843-2844.

-43 Vinceti M, Guidetti D, Pinotti M, Rovesti S, Merlin M, Vescovi L, Bergomi M, Vivoli G: Amyotrophic lateral sclerosis after long-term exposure to drinking water with high selenium content. Epidemiology 1996;7:529532.

44 Hozumi I, Hasegawa T, Honda A, Ozawa K, Hayashi Y, Hashimoto K, Yamada M, Koumura A, Sakurai T, Kimura A, Tanaka Y, Satoh M, Inuzuka T. Patterns of levels of biological metals in CSF differ among neurodegenerative diseases. J Neurol Sci 2011;303: 95-99.

$45 \mathrm{Hu}$ X, Yang Y, Su J, Yao C: Meta-analysis of the relationship between amyotrophic lateral sclerosis and susceptibility to serum ferritin level elevation. Neuroscience Riyadh Saudi Arab 2016;21:120-125.

-46 Arvidson B: Inorganic mercury is transported from muscular nerve terminals to spinal and brainstem motoneurons. Muscle Nerve 1992; 15:1089-1094.

-47 Chuu JJ, Liu SH, Lin-Shiau SY: Differential neurotoxic effects of methylmercury and mercuric sulfide in rats. Toxicol Lett 2007; 169:109-120.

-48 Sienko DG, Davis JP, Taylor JA, Brooks BR: Amyotrophic lateral sclerosis. A case-control study following detection of a cluster in a small Wisconsin community. Arch Neurol 1990;47:38-41.

49 Kapaki E, Segditsa J, Papageorgiou C: Zinc, copper and magnesium concentration in serum and CSF of patients with neurological disorders. Acta Neurol Scand 1997;79:373378.

50 Roos PM, Vesterberg O, Syversen T, Flaten TP, Nordberg M: Metal concentrations in cerebrospinal fluid and blood plasma from patients with amyotrophic lateral sclerosis. Biol Trace Elem Res 2013;151:159-170.

- 51 Roos PM, Lierhagen S, Flaten TP, Syversen T, Vesterberg O, Nordberg M: Manganese in cerebrospinal fluid and blood plasma of patients with amyotrophic lateral sclerosis. Exp Biol Med (Maywood) 2012;237:803-810.

-52 Vinceti M, Malagoli C, Fabbi S, Kheifets L, Violi F, Poli M, Caldara S, Sesti D, Violanti S, Zanichelli P, Notari B, Fava R, Arena A, Calzolari R, Filippini T, Iacuzio L, Arcolin E, Mandrioli J, Fini N, Odone A, Signorelli C, Patti F, Zappia M, Pietrini V, Oleari P, Teggi S, Ghermandi G, Dimartino A, Ledda C, Mauceri C, Sciacca S, Fiore M, Ferrante M: Magnetic fields exposure from high-voltage power lines and risk of amyotrophic lateral sclerosis in two Italian populations. Amyotroph Lateral Scler Frontotemporal Degener 201;18:583-589.
3 Malek A, Barchowsky A, Bowser R, HeimanPatterson T, Lacomis D, Rana S, Youk A, Talbott EO: Exposure to hazardous air pollutants and the risk of amyotrophic lateral sclerosis. Environ Pollut 2015;197:181-186.

54 Seelen M, Toro Campos RA, Veldink JA, Visser AE, Hoek G, Brunekreef B, van der Kooi AJ, de Visser M, Raaphorst J, van den Berg LH, Vermeulen RC: Long-term air pollution exposure and amyotrophic lateral sclerosis in Netherlands: a population-based case-control study. Environ Health Perspect 2017;125.

55 Tzivian L, Winkler A, Dlugaj M, Schikowski T, Vossoughi M, Fuks K, Weinmayr G, Hoffmann B: Effect of long-term outdoor air pollution and noise on cognitive and psychological functions in adults. Int J Hyg Environ Health 2015;218:1-11.

56 Brooks BR, Miller RG, Swash M, Munsat TL: El Escorial revisited: revised criteria for the diagnosis of amyotrophic lateral sclerosis. Amyotroph Lateral Scler Other Motor Neuron Disord 2000;1:293-299.

57 Cartographic and Geologic Institute of Catalonia. http://www.icgc.cat/en/ (last accessed on December 18, 2017).

58 Departament d'Agricultura, Ramaderia, Pesca i Alimentació. Crop Map DUN-SIGPAC [in Catalan]. http://agricultura.gencat.cat/ca/ serveis/cartografia-sig/aplicatius-tematicsgeoinformacio/sigpac/mapa-cultius/ (last accessed on December 18, 2017).

59 Department of Territory and Sustainability. Geoinformation. Air Quality Information http://dtes.gencat.cat/icqa/start.do?lang=en (last accessed on December 18, 2017).

60 Department of Territory and Sustainability. Technical Memories. Strategic Noise Maps. Barcelonès I and II, Baix Llobregat I and II, Vallès Occidental I and II, Gironès [in Spanish]. http://mediambient.gencat.cat/es/05_ ambits_dactuacio/atmosfera/contaminacio_ acustica/gestio_ambiental_del_soroll/ mapes_de_soroll/mapes_estrategics_de_soroll/index.html (last accessed on December $18,2017)$.

61 Directive 2002/49/EC of the European Parliament and of the Council of June 25, 2002 Relating to the Assessment and Management of Environmental Noise. http://eur-lex.europa. $\mathrm{e} \mathrm{u} / \mathrm{l}$ e g a l - c o n t e n t / E N / TXT/?uri=CELEX\%3A32002L0049 (last accessed on December 18, 2017).

62 OpenStreetMap https://www.openstreetmap. org/\#map=18/41.82816/2.89284 (last accessed on December 18, 2017).

63 Hoffmann R, Borsboom G, Saez M, Mari Dell'Olmo M, Burström B, Corman D, Costa D, Deboosere P, Domínguez-Berjón MF, Dzúrová D, Gandarillas A, Gotsens M, Kovács K, Mackenbach J, Martikainenn $\mathrm{P}$, Maynou L, Morrison J, Palència L, Pérez G, Pikhart H, Rodríguez-Sanz M, Santana P, Saurina C, Tarkiainen L, Borrell C: Social differences in avoidable mortality between small areas of 15 European cities: an ecological study. Int J Health Geogr 2014; 13:8.

64 INE. Instituto Nacional de Estadística. Indicators for census tracks. Population and Housing Census 2011 [in Spanish]. http:// www.ine.es/censos2011_datos/cen11_datos_ resultados_seccen.htm (last accessed on December 18, 2017).

65 Serra L, Juan P, Varga D, Mateu J, Saez M: Spatial pattern modelling of wildfires in Catalonia, Spain 2004-2008. Environ Model Software 2012;40:235-244.

66 Barceló MA, Varga D, Tobías A, Díaz J, Linares C, Saez M: Long term effects of traffic noise on mortality in the city of Barcelona, 2004-2007. Environ Res 2016;147:193-206.

-67 Salcedo N, Saez M, Bragulat B, Saurina C: Does the effect of gender modify the relationship between deprivation and mortality? BMC Public Health 2012;12:574.

68 IDESCAT https://www.idescat.cat/?lang=en (last accessed on December 18, 2017).

69 Lindgren F, Rue H, Lindström J: An explicit link between Gaussian fields and Gaussian Markov random fields: the stochastic partial differential equation approach (with discussion). J R Stat Soc Series B 2011;73:423-498. https://www.math.ntnu.no/inla/r-inla.org/ papers/spde-jrssb-revised.pdf (last accessed on December 18, 2017).

70 The R-INLA project. Random Walk Model of Order 1. http://www.math.ntnu.no/inla/r-inla.org/doc/latent/rw1.pdf (last accessed on December 18, 2017)

71 Richardson S, Thomson A, Best N, Elliott P: Interpreting posterior relative risk estimates in disease-mapping studies. Environ Health Perspect 2004;112:1016-1025.

72 Rue H, Martino S, Chopin N: Approximate Bayesian inference for latent Gaussian models by using integrated nested Laplace approximations (with discussion). J R Stat Soc Series B 2009;71:319-392. http://www.r-inla.org/ papers (last accessed on December 18, 2017).

73 R Core Team R: A language and Environment for Statistical Computing. R Foundation for Statistical Computing, Vienna, Austria 2017. https://www.R-project.org/ (last accessed on December 18, 2017).

74 R INLA project, 2017. http://www.r-inla.org/ home (last accessed on December 18, 2017).

75 QGIS http://qgis.org/en/site/ (last accessed on December 18, 2017).

76 Kilness AW, Hichberg FH: Amyotrophic lateral sclerosis in a high selenium environment. JAMA 1977;237:2843-2844.

-77 Proctor SP, Feldman RG, Wolf PA, Brent B, Wartenberg D: A perceived cluster of amyotrophic lateral sclerosis cases in a Massachusetts community. Neuroepidemiology 1992; 11:277-281.

78 Neilson S, Gunnarsson LG, Robinson I: Rising mortality from motor neurone disease in Sweden, 1961-1990: the relative role of increased population life expectancy and environmental factors. Acta Neurol Scand 1994; 90:150-159. 
79 Gunnarsson LG, Lygner PE, Veiga-Cabo J, de Pedro-Cuesta J: An epidemic-like cluster of motor neuron disease in a Swedish county during the period 1973-1984. Neuroepidemiology 1996;15:142-152.

80 Sabel CE, Boyle PJ, Loytonen M, Gatrell AC, Jokelainen M, Flowerdew R, Maasita P: Spatial clustering of amyotrophic lateral sclerosis in Finland at place of birth and place of death. Am J Epidemiol 2003;157:898-905.

81 Uccelli R, Binazzi A, Altavista P, Belli S, Comba P, Mastrantonio M, Vanacore N: Geographic distribution of amyotrophic lateral sclerosis through motor neuron disease mortality data. Eur J Epidemiol 2007;22:781-790.
82 Boumediene F, Druet-Cabanac M, Marin B, Preux PM, Allée P, Couratier P: Contribution of geolocalisation to neuroepidemiological studies: incidence of ALS and environmental factors in Limousin, France. J Neurol Sci 2011;309:115-122.

83 Spanish Ministry of Agriculture, Fisheries, Food and Environment. Metals [in Spanish]. http://www.mapama.gob.es/es/calidad-yevaluacion-ambiental/temas/atmosfera-ycalidad-del-aire/calidad-del-aire/salud/metales.aspx (last accessed on January 6, 2018).

84 Das K, Nag C, Ghosh M: Familial, environmental, and occupational risk factors in development of amyotrophic lateral sclerosis. $\mathrm{N}$ Am J Med Sci 2012;4:350-355.
85 WHO. Ozone and other photochemical oxidants. Air Quality Guidelines - Second Edition. WHO Regional Office for Europe, Copenhaguen, Denmark, 2000, Chapter 7.2.

86 Government of Aragon, Spain. When and where the highest levels of ozone occur [in Spanish]. http://www.aragonaire.es/ozone. php?n_action=highestlevels (last accessed on January 6, 2018).

87 Simpson DP, Rue H, Martins TG, Riebler A, Sørbye SH: Penalising model component complexity: a principled, practical approach to constructing priors (with discussion). Stat Sci 2017;32:1-28. 